\title{
Impacts of tree canopy structure on wind flows and fire propagation simulated with FIRETEC
}

\author{
François Pimont • Jean-Luc Dupuy • Rodman R. Linn • \\ Sylvain Dupont
}

Received: 5 March 2010 /Accepted: 20 July 2010 /Published online: 8 April 2011

(C) INRA and Springer Science+Business Media B.V. 2011

\begin{abstract}
- Introduction Forest fuel management in the context of fire prevention generally induces heterogeneous spatial patterns of vegetation. However, the impact of the canopy structure on both wind flows and fire behavior is not well understood.

- Material and methods Here, a coupled atmosphere wildfire behavior model, HIGRAD/FIRETEC, was used to investigate the effects of canopy treatment on wind field and fire behavior in a typical Mediterranean pine ecosystem.

- Discussion First, the treatment-induced winds were simulated with the model. We observed that with decreasing cover fraction the wind velocity increased within the treated zone. The wind spatial variability increased when the vegetation was aggregated into larger clumps. Fire simulations indicated that a decrease of fire intensity occurred after several meters of propagation in the treated zone. This intensity decrease was significant with a cover fraction below $25 \%$, but negligible with a cover fraction
\end{abstract}

Handling Editor: Dave Hibbs

F. Pimont $(\bowtie) \cdot$ J.-L. Dupuy

INRA. Institut National pour la Recherche Agronomique,

Ecologie des Forêts Méditerranéennes,

Equipe de Physique et Ecologie du feu,

UR 629,

F-84914 Avignon, France

e-mail: pimont@avignon.inra.fr

R. R. Linn

Los Alamos National Laboratory MS: D401,

Los Alamos, NM 87544, USA

S. Dupont

INRA, UR1263 EPHYSE, 71 avenue Edouard Bourlaux,

F-33883 Villenave d'Ornon, France greater than $50 \%$. The treatment also induced a more significant inclination of the plume away from vertical. The size of the tree clumps did not show significant effects on fire behavior.

- Conclusion This study was a preliminary investigation of wind/fire interaction over various canopy treatments, by using a physically based model. It gives some practical considerations for discerning the appropriate cover fraction and open perspectives for further investigations.

Keywords Canopy structure · Forest fire · Windflow · Modeling · FIRETEC

\section{Introduction}

Fuel management, including fuel reduction and segregation of pockets of fuel, is frequently used to reducing fire intensity and crowning (Xanthopoulos et al. 2006). Fuel management often results in heterogeneous spatial patterns of vegetation. A better understanding of the fuel spatial patterns effects on fire intensity and crowning is frequently sought by forest managers to help management planning. Several case studies of fuel-break impacts on fire behavior can be found in the literature (Lambert et al. 1999; Finney et al. 2007).

Among modeling studies, physics-based models have been used to assess fire propagation in various fuel treatments (Dupuy and Morvan 2005; Linn et al. 2005; Pimont et al. 2006). Parsons (2007) performed a statistical analysis of a set of numerical simulations of fire moving across fuel breaks. However, detailed numerical studies of physical processes occurring as winds or fire transition from forest to treated areas and back to forest have not been performed. 
Accurate wind simulations are generally considered to be critical for fire behavior prediction (Butler et al. 2006). In canopies, wind flows are dominated by turbulent mixing, with intermittent strong downward gusts developing as in a plane mixing layer flow (Finnigan 2000). The presence of clearings of several times the height of the canopy and of fuel treatments that result in increased distances between crowns and low cover fraction, affect significantly the wind flow (Raupach et al. 1987; Lee 2000).

The HIGRAD/FIRETEC modeling system is a threedimensional two-phase transport model that solves the conservation equations for mass, momentum, energy, and chemical species. A detailed description of the physical and chemical formulation of the model (hereafter referred to as FIRETEC) is available in Linn and Cunningham (2005) and Pimont et al. (2009). FIRETEC represents threedimensional structure of vegetation at $\sim 2 \mathrm{~m}$ scales and resolves fluctuating winds within and above the canopy at the same scales by using a large eddy simulation approach. In previous studies, it has been shown that this model is useful for investigating the impact of fuel structure on fire behavior (Linn et al. 2005; Pimont et al. 2006), and that it simulates accurately flows and turbulence over complex fuel configurations such as fuel breaks (Pimont et al. 2009).
Because of these attributes, a physically based coupled fire/ atmosphere model such as FIRETEC can be a valuable tool for the investigation of the fuel treatment effects.

In the present study, FIRETEC is used to assess the impact of canopy treatments on both wind flows and fire behavior, in an exploratory study of a typical Mediterranean pine ecosystem. After a description of the numerical simulations, the sensitivity of the wind field and fire behavior to the parameters characterizing the fuel treatment is analyzed. Then, the relevance of the simulation results is discussed in terms of comparisons with previous observations, as well as consequences of fuel-break design on fire behavior, modeling, and prevention.

\section{Material and methods}

\subsection{Fuel complexes}

The computational domain represented a $640 \times 320 \mathrm{~m}$ forest with a horizontal resolution of $2 \mathrm{~m}$. A portion of the canopy, stretching across the domain in the crosswind direction between 240 and $440 \mathrm{~m}$ from the domain inlet, was considered as the "treated zone" (Fig. 1). Seven types
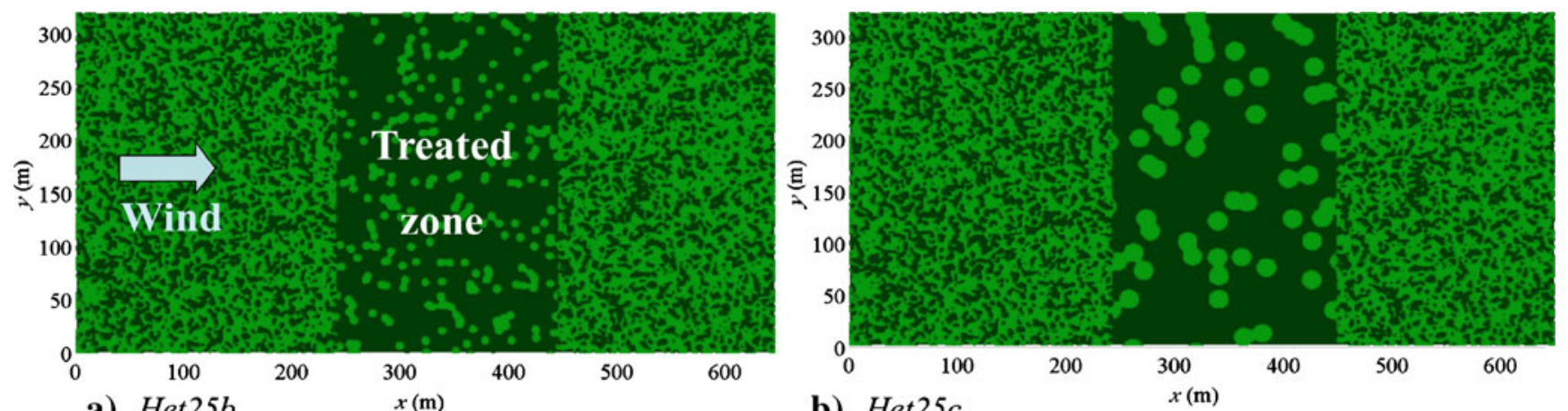

a) $\operatorname{Het} 25 b$

b) $\operatorname{Het} 25 \mathrm{c}$
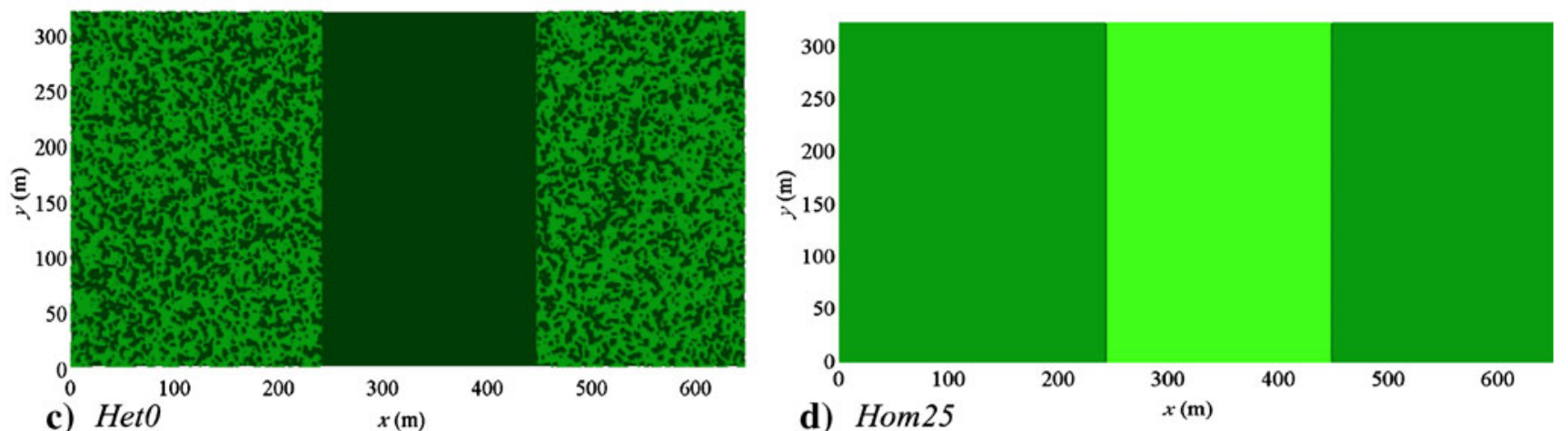

c) $\mathrm{HetO}$

Homogenized canopy in Hom 25

Pine canopy in heterogeneous cases

Understorey

Fig. 1 Downward-looking view of selected plots from an elevated upwind location 
of treated zone have been considered in this study, by varying (1) tree cover fractions $C$, from $0 \%$ to $75 \%$ (referred hereafter as Het0, Het25, Het50, Het75) with various aggregations, and (2) clump size $L$, by considering three values: 4, 10, and $20 \mathrm{~m}$ (labeled: a, b, c; Table 1). Clump size effects were investigated at low cover fraction only $(25 \%)$, because a canopy with a high cover fraction has small gaps at all clump sizes. A homogenized fuel (Hom 25) was also designed with the same load as Het25 cases within the forest and treated zone. It can be envisioned as infinitely small clump size cases.

The non-treated forest, referred hereafter as "forest", is similar in all simulations (except Hom 25 which is homogenized). It is modeled as a canopy with a height $h=12 \mathrm{~m}$ and a crown base height of $4.5 \mathrm{~m}$. The tree canopy was made of cylindrical trees with individual crown diameters of $4 \mathrm{~m}$, a bulk density of $0.1 \mathrm{~kg} \mathrm{~m}^{-3}$ and a moisture content of $100 \%$. They were randomly distributed with a cover fraction $C=75 \%$, which is representative of dense natural pine forests. The fuel load was $0.54 \mathrm{~kg} \mathrm{~m}^{-2}$ and the leaf area index (LAI) was 2.9, which is typical of Aleppo pine stands (Mitsopoulos and Dimitrakopoulos 2007). The understory was a homogeneous shrubland of $0.5 \mathrm{~m}$ height, $1 \mathrm{~kg} \mathrm{~m}^{-3}$ bulk density, and 70\% moisture content.

\subsection{Wind simulations}

The wind flows were simulated under the same conditions as those used by Pimont et al. (2009). The reference wind intensity in the open area was about $8 \mathrm{~ms}^{-1}$ at $12 \mathrm{~m}$ high, which could be considered as a moderate to strong ambient wind. This ambient wind was used to set the initial conditions in the model, which includes a drag force and a turbulence model in order to compute realistic flows inside and above the canopy according to its leaf area density. Initial wind conditions used a logarithmic velocity profile and its direction was parallel to the $x$-axis. Neutral atmospheric stability was assumed with a potential temperature of $300 \mathrm{~K}$. For these wind calculations, the time step was $0.04 \mathrm{~s}$. Lateral boundary conditions were cyclic. A Rayleigh damping layer was used at the top of the domain. The $440 \mathrm{~m}$ of forest sections were greater than a $35 h$ length, which was long enough to obtain wind flows that recover from the influences of one fuel break before winds reached the next fuel break (Chen et al. 1995, Lee 2000).

Mean flow fields presented hereafter were deduced from the simulated instantaneous fields by averaging them on one simulated hour.

\subsection{Fire simulations}

A fire line was ignited in the upwind forest area. The ambient conditions including evolving series of turbulent fluctuations were fed at domain boundaries from the computed wind fields described above, to reproduce realistic ambient conditions, including well-developed resolved turbulent structures. Cyclic boundary conditions in the $y$-direction were used in order to simulate an infinite fire line approaching infinitely long fuel break. This assumption simplifies the analysis of fire behavior, by eliminating impacts of fire-line length and corresponding shapes.

The fire behavior was not only mainly characterized by fire intensity, but also plume inclinations and temperatures. In three-dimensional simulations, the temporal and spatial

Table 1 Spatial characteristics of canopy fuel on the treated zones

\begin{tabular}{|c|c|c|c|c|c|}
\hline Case & $\rho^{\mathrm{a}}\left(\mathrm{kg} \mathrm{m}^{-3}\right)$ & $L^{\mathrm{b}}(\mathrm{m})$ & $C^{\mathrm{c}}(\%)$ & $\mathrm{LAI}^{\mathrm{d}}$ & $\operatorname{Load}^{\mathrm{e}}\left(\mathrm{kg} \mathrm{m}^{-2}\right)$ \\
\hline Het75a (no treatment) & 0.1 & 4 & 75 & 2.9 & 0.54 \\
\hline Het50a & 0.1 & 4 & 50 & 1.9 & 0.36 \\
\hline Het $25 a$ & 0.1 & 4 & 25 & 0.97 & 0.18 \\
\hline Het $25 b$ & 0.1 & 10 & 25 & 0.97 & 0.18 \\
\hline Het $25 c$ & 0.1 & 20 & 25 & 0.97 & 0.18 \\
\hline Hom 25 & 0.025 & 0 & 100 & 0.97 & 0.18 \\
\hline Heto & 0.0 & - & 0 & 0.0 & 0.0 \\
\hline
\end{tabular}

Het0, Het 25a, Het50a and Het $75 a$ have treated zones with $2 \mathrm{~m}$ clumps and cover fraction of respectively $0 \%, 25 \%, 50 \%$, and $75 \%$. Het $25 b$ and $H e t 25 c$ have treated zones with cover fraction of $25 \%$ with clumps of 5 and $10 \mathrm{~m}$. Hom 25 has homogeneous fuel with same load as Het $25 a, b$, and $c$

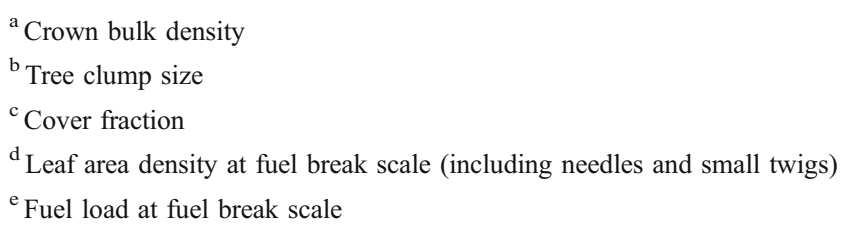


variability of the different instantaneous variables is significant compared to their mean values as also seen in experiments (Morandini et al. 2006). With its long fireline assumption, this modeling study is able to compute spatial and temporal averages from three-dimensional fields, to understand general features of the plume.

\section{Results}

\subsection{Wind simulations}

A two-dimensional view of instantaneous wind field at $z=6.5 \mathrm{~m}$ along the forest-treated zone-forest pattern is presented in Fig. 2. It illustrates the channeling of the wind, which results in some wind accelerations in corridors between fuel clumps in the treated zone, with the development of elongated eddy structures at the canopy top.

Figure 3 represents the mean vertical streamwise velocity profile in the middle of the treated zone for different values of cover fraction and clump size. In case $H e t 75 a$ (no treatment), the profile was characterized by an inflection near $z=2 / 3 h$. In thinned cases, the fuel reduction was associated with a lower average drag force over the treated zone that induced an increase of mean streamwise velocity compared to the forest values. The effect of the canopy structure happened between heights of 0 and $2 \mathrm{~h}$. The profile inflection was less severe with decreasing cover fraction and completely disappeared in Heto (Fig. 3a). A $25 \%$ (Het $25 a$ ) cover fraction resulted in wind speeds that were $0.25-0.5$ of those in no canopy case.

The increase of the clump size $L$ (from 4 to $20 \mathrm{~m}$ ) induces a slight increase of mean streamwise velocity

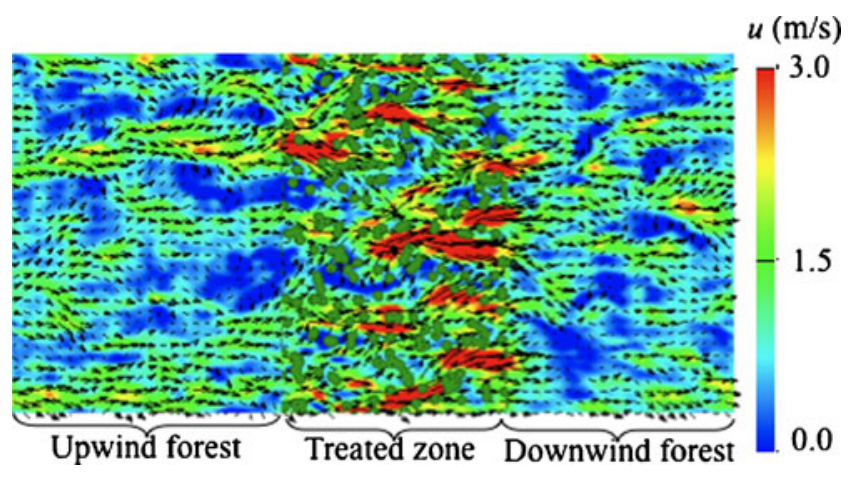

Fig. 2 Top view of the flows within the canopy $(z=6.5 \mathrm{~m})$ for Het $25 \mathrm{~b}$, at $t=4000 \mathrm{~s}(640 \times 320 \mathrm{~m})$ The color map was used to represent the instantaneous streamwise component of the wind velocity, $u$. The vectors represent the horizontal flow components. Green circles represent the tree clumps on the treated zone. For visualization reasons, trees were represented only on this zone and not in upwind and downwind forested areas, where their cover fraction $(75 \%)$ would have obscured the wind field
(Fig. 3b). Indeed, larger clumps induced larger gaps for a same cover fraction. The wind had more tendency to channel in the gap when the clumps are larger. The homogeneous case (hom 25) was associated with the lowest mean streamwise velocities, which was consistent with the notion that the homogenized fuel bed can be thought of as having very small clump. The magnitude of clump size effect on mean flow was far less significant than the cover fraction effect. However, the clump size affected the spatial variability of the mean streamwise velocity as indicated by normalized standard deviation profiles of the mean wind velocity along the spanwise direction (Fig. 4). The velocity variability was lower than $5 \%$ of the mean velocity in cases where vegetation was homogeneous (Het0, Hom 25), but increased with the clump size in heterogeneous canopy to reach $30 \%$ at $2 / 3 \mathrm{~h}$ in $\mathrm{Het} 25 \mathrm{c}$, and was associated with more channeling between trees.

\subsection{Fire simulations}

Figure $5 \mathrm{~b}-\mathrm{d}$ illustrates for the Het $25 a$ case the fire propagation from the upwind forest area, through the treated zone, and into the downwind forest area. Figure 5a illustrates the $y$-averaged fire intensity as a function of position $x$ relative to the domain inlet. The fire intensity increased after ignition until the quasi-steady fire propagation was established. The movement into the treated zone was associated with a decrease in fire intensity. Its minimum value was obtained when the fire had traveled $60 \mathrm{~m}$ into the treated zone. As the fire traveled downwind beyond the leading edge of the downwind forest, the fire intensity increased up to the same values as in the upwind forest area, before decreasing again when the fire reached the end of the domain. The rate of spread was close to $0.8 \mathrm{~ms}^{-1}$, with no significant modification over the treated zone. Some strips of fuel remained minimally affected by the fire (Fig. 5d). A close-up image on an area where these strips were present reveals that they were tied to coupled fire/atmosphere-induced vortices (Fig. 6), characterized by a downward flow above the strips of fuel that are left and an upward flow above the torching regions. The width of these vortices was about $30-50 \mathrm{~m}$.

Figure 7 illustrates the variation of the fire intensity over the path for different cover fractions (a) and clump sizes (b). The leveling of the lines relative to their initial climbs indicates the attainment of a quasi-steady state. Some differences can be seen in the intensity level reached before the treated zone, due to small differences in flow fields. As expected, the intensity within the treated zone decreased with cover fraction (Fig. 7a). An analysis of variance of intensity values on the treated zone as a function of covers was highly significant $(F$ value $=98.3 ; \operatorname{Pr}(F)<2.2$ e-16) and Tukey's test showed that mean intensities on treated zone 
Fig. 3 Vertical profiles of mean streamwise velocity in the middle of the treated zone $(x=340 \mathrm{~m})$, for different cover fractions and clump sizes. Het 0 , Het 25a, Het50a and Het $75 a$ have treated zones with $2 \mathrm{~m}$ clumps and cover fraction of respectively $0 \%, 25 \%, 50 \%$, and $75 \%$. Het $25 b$ and Het $25 c$ have treated zones with cover fraction of $25 \%$ with clumps of 5 and $10 \mathrm{~m}$. Hom 25 has homogeneous fuel with same load as Het $25 a, b$, and $c$

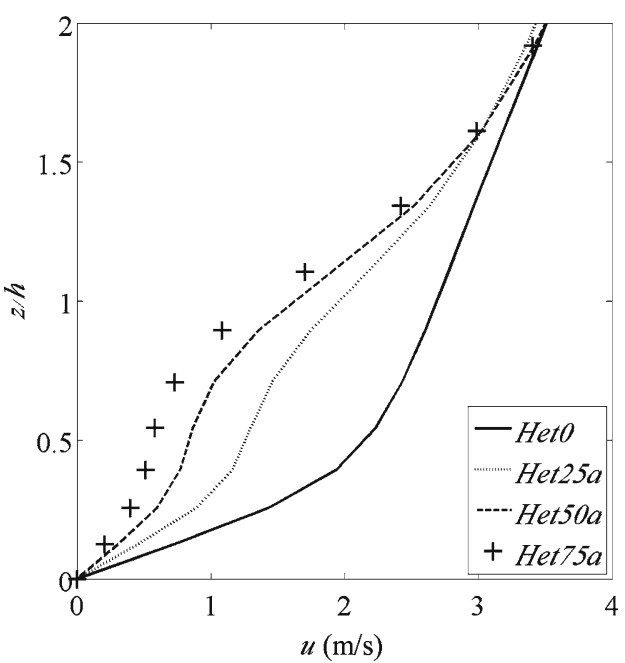

a) Cover fraction effect

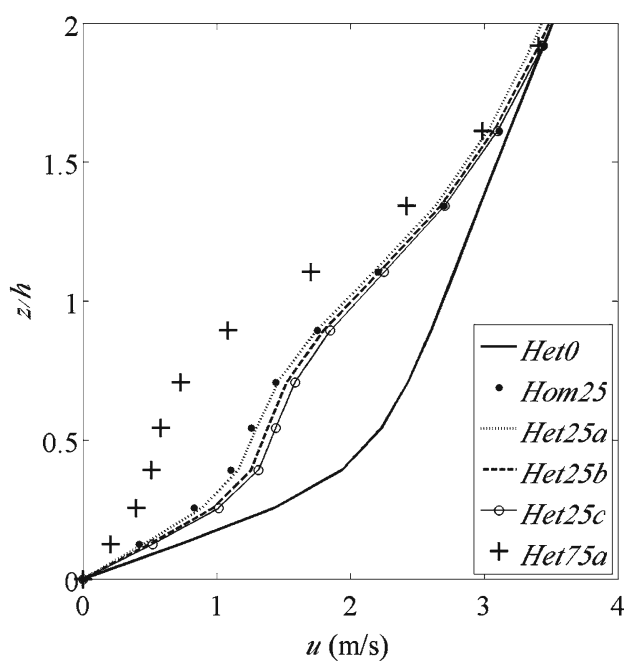

b) Clump size effect differ for the different cover fraction (95\% confidence intervals). However, it is worth noting that a fuel reduction to the level of $50 \%$ cover fraction (from the initial $75 \%$ ) had minimal effect on fire intensity, whereas a reduction to $25 \%$ had a significant effect. The effects of clump size on averaged fire intensity were almost negligible at $25 \%$ cover fraction (Fig. 7b). An analysis of variance of intensities as a function of covers was not significant $(F$ value $=2.16 ; \operatorname{Pr}(F)<0.145)$. Hom 25 tends to decrease fire intensity, as well as flame heights, but differences were small and not significant.

The details of the local fire behavior can be very complex, as shown in Fig. 6. To describe the mean fire behavior, $y$-average velocity vectors were derived from instantaneous velocity components in the middle of the treated zone. Figure 8 depicts velocity vectors in the shrub layer $(z=0.75 \mathrm{~m})$ and close to mid-canopy height $(z=6.5 \mathrm{~m})$.

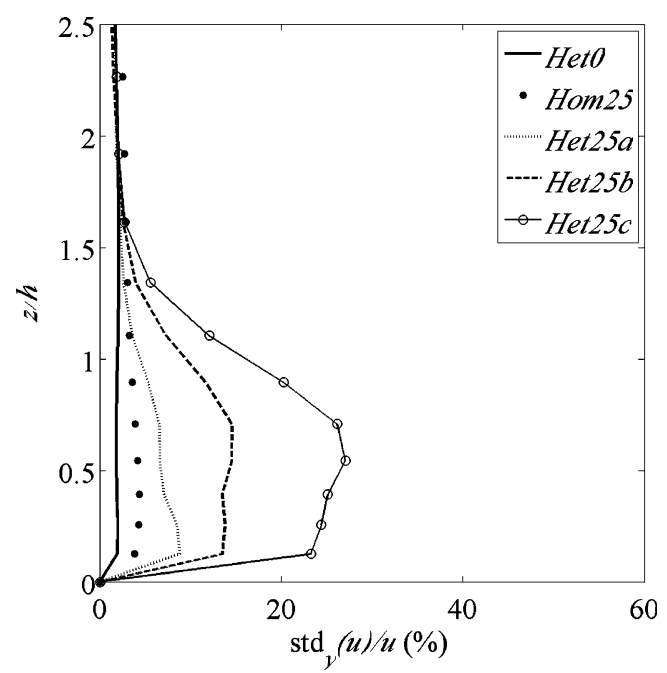

Fig. 4 Effects of clump size $L$ on the standard deviation of the mean wind velocity (in percentage of $u$ ) along the cross wind direction, in the middle of the treated area
In this figure, the position $x=0 \mathrm{~m}$ corresponds to the firefront position in the shrub layer. At the two considered heights, the position of the plume is related to the location of positive vertical velocity components. The plume was more horizontal with lower cover fraction. $15 \mathrm{~m}$ downwind to the fire at heights below $1.5 \mathrm{~m}$, the gas temperatures in the treated zone were $10-20^{\circ} \mathrm{C}$ higher for lower cover fractions. This result might seem surprising since fire intensity was higher with a higher cover fraction, but this facet of the results is a consequence of the more horizontal trajectory of the hot gases with low canopy cover, which induced higher temperatures downwind.

\section{Discussion}

\subsection{Simulations versus experimental data}

The model used here for wind computation above and within the canopy has already been validated against experimental data in the context of homogeneous canopy and fuel break (Pimont et al. 2009). The results obtained here were consistent with this previous study, as well as others. For example, the wind acceleration mainly took place in the first $100 \mathrm{~m}$ of the treated zone, i.e., between 8 and $10 \mathrm{~h}$, which is in agreement with Chen et al. (1995) or Lee (2000).

Observed crown fire intensities usually range between 8,000 and $40,000 \mathrm{kWm}^{-1}$ (Trabaud 1989). In our simulations, intensities were close to $8,000 \mathrm{kWm}^{-1}$. This relatively low value can be explained by the moderate wind, but also low fuel loads in Aleppo pine canopies, that induced mostly torching. Indeed, simulations done in the same configuration with heavier load provided intensity of more than $35,000 \mathrm{kWm}^{-1}$ (result not shown). The average rate of spread was not significantly affected by canopy fuel 
Fig. 5 a Fire intensity variation along the forest-treated zoneforest pattern (case het25: $\mathrm{C}=25 \%, L=4 \mathrm{~m})$. Fire behavior at three locations: within the upwind forest (b), within the treated zone (c), and within the downwind forest (d)

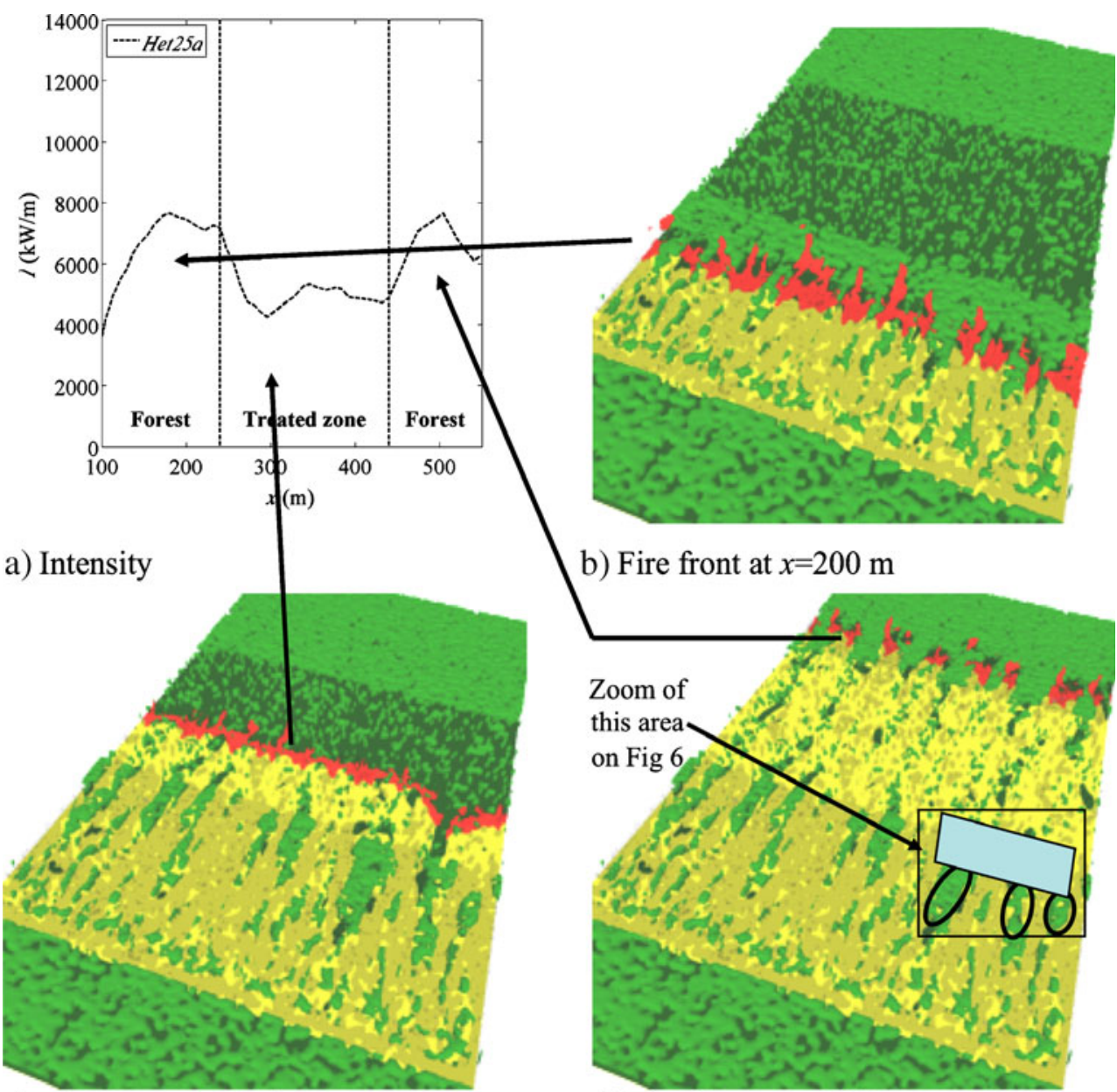

c) Fire front at $x=300 \mathrm{~m}$

d) Fire front at $x=500 \mathrm{~m}$ structure and generally ranged around $0.8 \mathrm{~ms}^{-1}$, for a wind speed equivalent to $8 \mathrm{~ms}^{-1}$ in open area. In similar wind conditions, Taylor et al. (2004) reported mean rates of fire spread of $0.4-0.9 \mathrm{~m} / \mathrm{s}$ in Canadian pine forests. Rate of spread tends to increase with fire front length (Cheney et al.
1998; Linn and Cunningham 2005), because a large front prevents lateral indrafts that can cool the fuel in front of the fire. In the present simulations, the fire line was considered infinite, which may explain why our predicted spread rates were in the upper part of Taylor et al.'s range.
Fig. 6 Upwind view of (looking at the back of the fire) flow fields above the firefront (white) for case Het25a $(t=190 \mathrm{~s}$ after ignition). This view is a zoom of the window represented in Fig $5 \mathrm{~d}$. The flow field is represented in the vertical $(y-z)$ plane $x=216 \mathrm{~m} ; v$ and $w$ components are represented by the vectors and $w$ is also represented by the color map

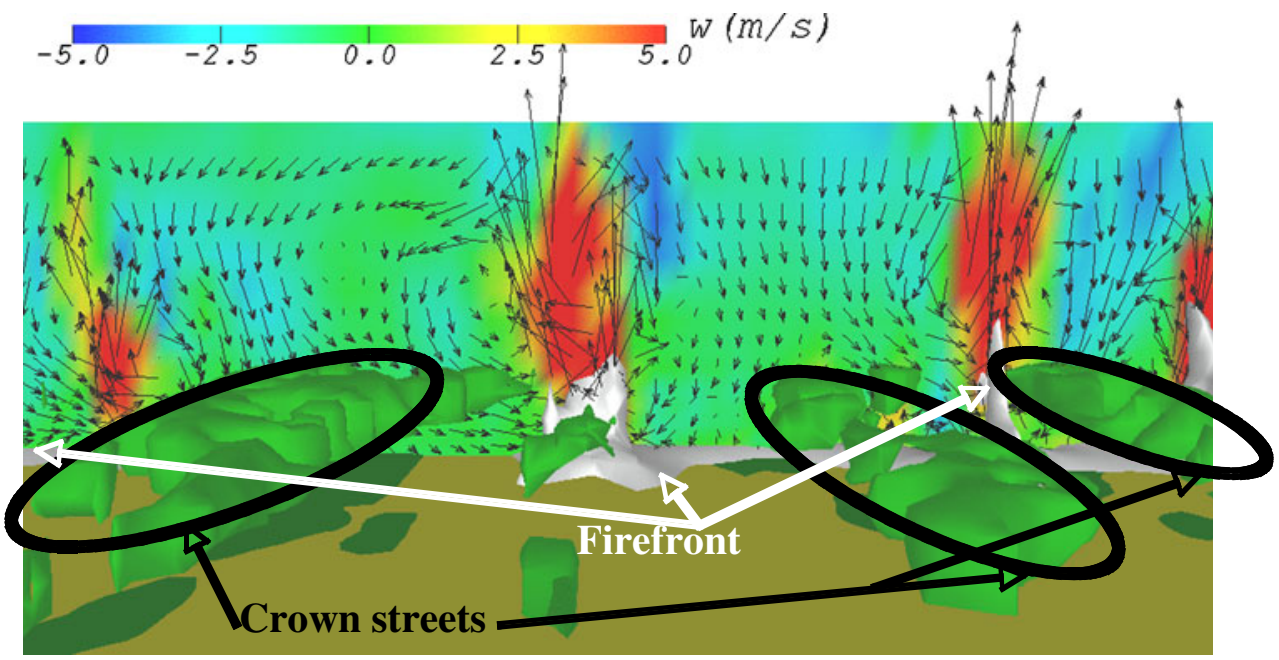


Fig. 7 Fire intensities along the forest-treated zone-forest pattern for different cover fractions (a) and clump size (b). Het 0 , Het 25a, Het50a, and Het75a have treated zones with $2 \mathrm{~m}$ clumps and cover fraction of respectively $0 \%, 25 \%, 50 \%$, and $75 \%$. Het $25 b$ and Het $25 c$ have treated zones with cover fraction of $25 \%$ with clumps of 5 and $10 \mathrm{~m}$. Hom 25 has homogeneous fuel with same load as Het25a, $b$, and $c$

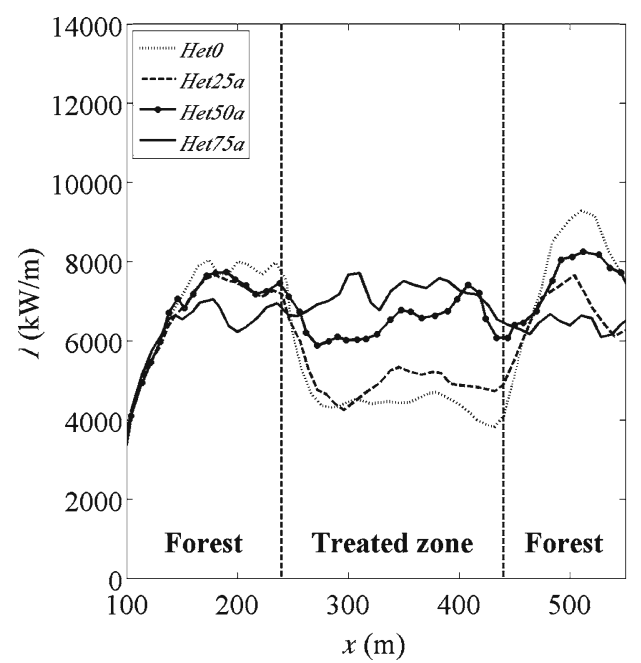

a) Cover fraction effect

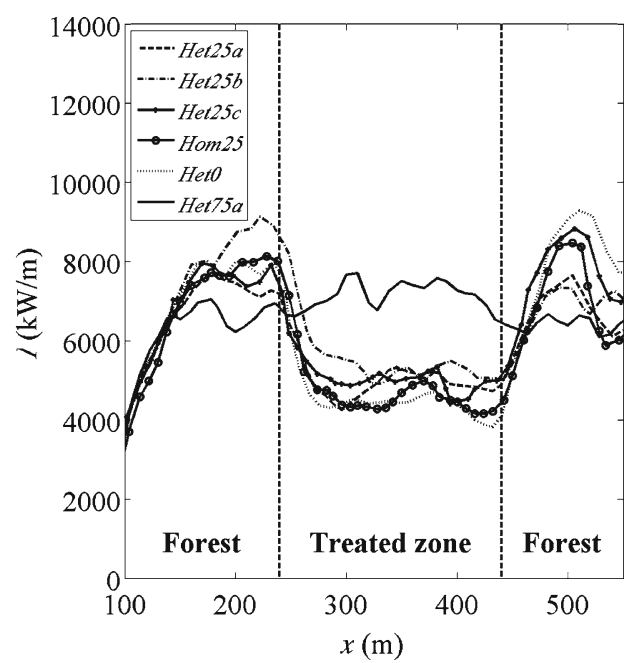

b) Clump size effect

\subsection{Treatment effects on wind}

For a given fuel load, the average flow velocity increased with clump size. It should be noted that other computation done at higher LAI (8) reveals more significant effects on mean flow. In the present Aleppo pine ecosystem, the spatial variability of velocity increases with increasing clump size, due to channeling between clumps. When gaps were large, the fast winds from above the canopy had more
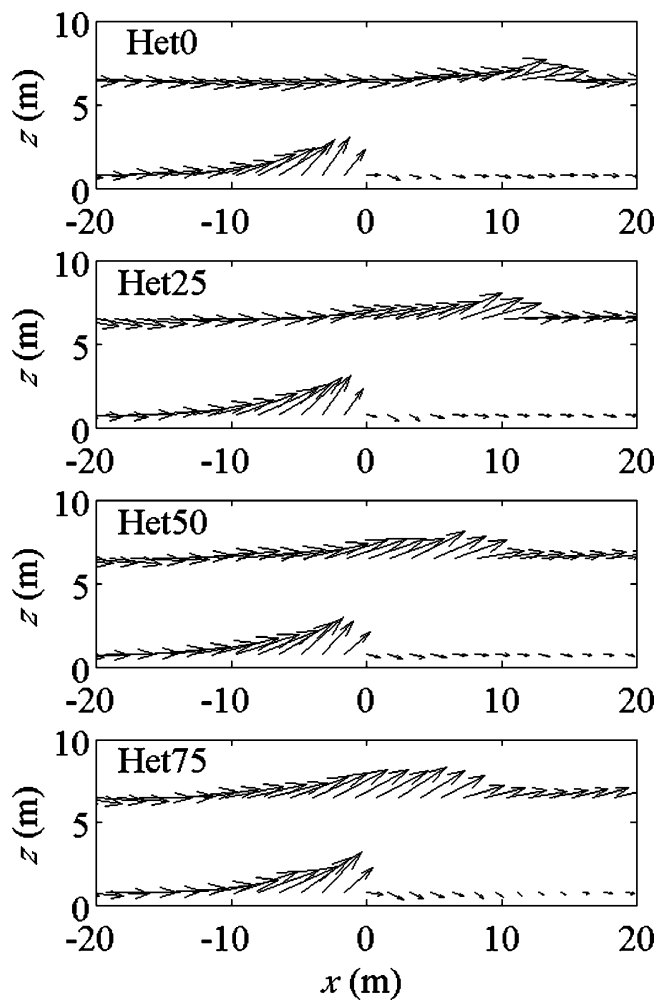

Fig. 8 Averaged flow vectors for different cover fractions on the treated zone. The position $x=0 \mathrm{~m}$ corresponds to the fire head position opportunity to be easily entrained into the canopy space. In our simulation, the mean gap size could reach $5 h$ (Het $25 c)$ and induced $30 \%$ of spatial variability. Comparing homogenized forest ("forest zone" of Hom 25) with Het75 reveals no significant effects on wind characteristics of heterogeneity for a $75 \%$ canopy cover. This is in agreement with results of Patton (1997), who reports negligible heterogeneity effects with canopy cover of $90 \%$. In these cases, gap size was significantly smaller than $h$. To our knowledge, the effect of gaps between $h$ and $5 h$ on the wind flow at low cover fraction in terms of mean flow and spatial variability has not been investigated before.

\subsection{Treatment effects on fire}

At the landscape scale, the treated zone induced a strong heterogeneity. Transition between forest to treated zone and back induced an adjustment of the fire behavior occurring over $50 \mathrm{~m}$ distance in downwind direction.

The rate of spread of the long fire line considered in this study was not significantly affected by heterogeneity. The decrease of fire intensity caused by the fuel load reduction could have resulted in a reduction of heat transfer to vegetation, because of the reduction of heat source strength. However, the wind pattern induced a more horizontal plume, which in turn advects more hot gasses over the vegetation and increases the heat transfer. This probably explains why the rate of spread was not strongly modified. In the case of a clean fuel break (with surface fuel cleared), this increase of wind speed in channels is likely to increase the fire spread.

Treatments tend to decrease fire intensity, with threshold values for cover fraction ranging between $25 \%$ and $50 \%$. However, the presence of relatively heavy fuel load in the understory enhanced a high fire intensity. In Mediterranean region, the shrubland is very dynamic so that such loads 
can be reached between 3 and 6 years after treatment (Trabaud et al. 1985). Canopy treatments by themselves are clearly insufficient for efficient fire prevention and a frequent clearing of the understory is required. Our study also illustrates how the presence of a few remaining trees ( $25 \%$ cover) on the treated zone helped to keep the plume vertical and to reduce downwind temperature, without increasing fire intensity significantly. This behavior can probably be extrapolated to fuel breaks with cleared understory and be a way to improve the fire fighter safety. However, it should be kept in mind that these pines can be a source of spotting.

Finally, forest homogenization (hom 25) was not significantly different from the heterogeneous cases het 25 . This suggests that in this ecosystem, detailing the crown structure is not very significant for propagation assessment. However, other simulations ran at heavier load (between 1 and $2 \mathrm{~kg} \mathrm{~m}^{-2}$, results not shown) reveals significant differences, so details of canopy structure could have more significance in ecosystems with larger fuel loads.

\section{Conclusion}

This study was a first investigation of wind/fire interaction over various canopy treatments, by using a physically based model that explicitly takes into account fuel description at tree clump scale. This work illustrates how fuel heterogeneity affects fire as well as wind. It gives some practical considerations for discerning the appropriate cover fraction, taking into account the fire intensity, but also the plume angle. Further works and investigations on fuel breaks (including shrub clearing) with such models should define rules for fuel management in the future.

Acknowledgments This study has been partially funded by the European Commission in the frame of the FIREPARADOX research program (contract FP6-018505) and the large computations for this work have been made possible by the Los Alamos National Laboratory Institutional Computing resources. This work has also leveraged contributions from INRA and LANL/USFS efforts.

\section{References}

Butler B, Forthofer J, Finney M, McHugh C, Stratton R, Bradshaw L (2006) The impact of high resolution wind field simulations on the accuracy of fire growth predictions. For Ecol Manag 234S: $\mathrm{S} 85$

Chen JM, Black TA, Novak MD, Adams RS (1995) A wind tunnel study of turbulent airflow in forest clearcuts. In: Coutts MP,
Grace J (eds) Wind and trees. Cambridge University Press, London, pp 71-87

Cheney NP, Gould JS, Catchpole WR (1998) Prediction of fire spread in grasslands. Int J Wildland Fire 8(1):1-13

Dupuy JL, Morvan D (2005) Numerical study of a crown fire spreading toward a fuel break using a multiphase physical model. Int J Wildland Fire 14(2):141-151

Finney MA, Selia RC, McHugh CW, Ager AA, Bahro B, Agee JK (2007) Simulation of long-term landscape-level fuel treatment effects on large wildfires. Int J Wildland Fire 16:712-727

Finnigan J (2000) Turbulence in plant canopies. Annu Rev Fluid Mech 32:519-571

Lambert B, Casteignau D, Costa M, Etienne M, Guiton J-L, Rigolot R (1999) Analyse après incendie de six coupures de combustible. Réseau Coupures de Combustible. Editions de la Cardère $85 \mathrm{p}$.

Lee X (2000) Air motion within and above forest vegetation in nonideal conditions. For Ecol Manag 135:3-18

Linn RR, Cunningham P (2005) Numerical simulations of grass fires using a coupled atmosphere-fire model: basic fire behavior and dependence on wind speed. J Geophys Res. doi:10.1029/ 2004JD005597

Linn RR, Winterkamp J, Colman JJ, Edminster C, Bailey J (2005) Modeling interactions between fire and atmosphere in discrete element fuel beds. Int J Wildland Fire 14:37-48

Mitsopoulos ID, Dimitrakopoulos AP (2007) Canopy fuel characteristics and potential crown fire behavior in Aleppo pine (Pinus halepensis Mill.) forests. Ann For Sci 64:287-299

Morandini F, Silvani X, Rossi L, Santoni P, Simeoni A, Balbi J-H, Rossi J-L, Marcelli T (2006) Fire spread experiment across Mediterranean shrub: influence of wind on flame front properties. Fire Safety J 41:229-235

Parsons, RA (2007) Spatial variability in forest fuels: simulation modeling and effects on fire behavior. Thesis. University of Montana-Missoula. College of Forestry and Conservation 255 pp.

Patton, EG (1997) Large-eddy simulation of turbulent flow above and within a plant canopy. PhD Dissertation. University of California, Davis, USA. 145p

Pimont F, Linn RR, Dupuy J-L, Morvan D (2006) Effects of vegetation description parameters on forest fire behavior with FIRETEC. For Ecol Manag 234 S S120

Pimont F, Dupuy J-L, Linn RR, Dupont S (2009) Validation of FIRETEC wind-flows over a canopy and a fuel-break. Int $\mathrm{J}$ Wildland Fire 18:775-790

Raupach MR, Bradley EF, Ghadiri H (1987) A wind tunnel investigation into aerodynamic effect of forest clearing on the nesting of Abbott's Boody on Christmas Island. Internal report, Csiro Centre for Environmental Mechanics, Canberra

Taylor SW, Wotton BM, Alexander ME, Dalrymple GN (2004) Variation in wind and crown fire behavior in a northern jack pine-black spruce forest. Can J For Res 34:1561-1576

Trabaud L (1989) Les feux de forêts. Editions France Sélection 278 p.

Trabaud L, Grosman J, Walter T (1985) Recovery of burnt Pinus halepensis MILL forests. I. Understorey and litter phytomass development after wildfire. For Ecol Manag 12:269-277

Xanthopoulos G., Caballero D., Galante M., Alexandrian D., Rigolot E., Marzano R., Forest fuel management in Europe. In: Andrews P.L., Butler B.W. Fuels Management-how to measure success: Conference proceedings. (2006), 28-30 March. Portland,OR. Proceedings RMRS-P-41. Fort Collins, CO, USDA Forest Service, Rocky Mountain Research Station. 